\title{
Panxian Dadong, South China: Establishing a Record of Middle Pleistocene Climatic Changes
}

\section{$\boldsymbol{\Delta} \cdot \boldsymbol{\Delta} \cdot \boldsymbol{\Delta}$}

\author{
WANG WEI, LIU JUN, HOU YAMEI, SI XINQIANG, HUANG WEIWEN, \\ LYNNE A. SCHEPARTZ, AND SARI MILLER-ANTONIO
}

Study of the Chinese and Southeast Asian Pleistocene environment has been greatly enriched by the combined use of geological, geographical, biostratigraphic, and chemical analyses. A major focus has been on understanding the influence of the uplift of the Qinghai-Tibet Plateau on the development of the East Asian monsoon climatic regime and the identification of climatic oscillations throughout the Pleistocene. The Quaternary climates of South and Southwest China are not as well known as those of the east or north, but it appears that the effects of the environment on the formation of the extensive and remarkable southern karst landscape were not as marked as they were in the north. Most notably, the strong scouring actions of the continental ice sheets are absent in the south (Yuan et al. 1995). Instead, as the Qinghai-Tibet Plateau rose during the Quaternary, the karst landscape of South and Southwest China was largely sculpted by major rivers that had their origins in the high plateau mountain ranges (Sweeting 1995).

Most reconstructions of Asian Pleistocene climate change are based on interpretations of loess-paleosol sequences (especially the Luochuan loess of North China [Liu et al. 2000]), where loess deposits are viewed as forming under drier climatic conditions and paleosols are seen as forming during wetter, warmer periods. Therefore, paleoclimatic reconstruction in South China currently depends on making use of information about widespread climatic effects such as the monsoon weather patterns. Paleoclimatic inference is becoming more refined, however. Studies incorporating magnetic susceptibility (Chen et al. 2003) and mineralogic correlations with magnetic susceptibility (Ji et al. 2001) have been very useful for more precise paleoclimatic reconstruction. All of these different techniques are documenting major climatic oscillations and rapid environmental transitions. For example, the work of Ding et al. (1999) on Middle Pleistocene climatic instability

Wang Wei is with the Chinese University of Geosciences in Wuhan; Liu Jun and Si Xinqiang are with the Cultural Relic Management Bureau of Liupanshui City; Hou Yamei and Huang Weiwen are with Chinese Academy of Sciences, Institute of Vertebrate Paleontology and Paleoanthropology in Beijing; Lynne A. Schepartz is with the Department of Anthropology, University of Cincinnati, Ohio; and Sari Miller-Antonio is with the Department of Anthropology/Geography of the California State University, Stanislaus.

Asian Perspectives, Vol. 43, No. 2 (C) 2004 by the University of Hawai'i Press. 
utilized a technique based on grain size of particles in soil cores to reconstruct a high-resolution record of climate changes during the last two glacial-interglacial cycles. They found frequent, large magnitude climatic oscillations during the penultimate glaciation (ending between 130-140 kya) that were not characteristic of the last interglacial, illustrating that these glacial periods had much more variable climate. Other evidence for climatic fluctuations during these times is documented in changes in the mollusk species distributed throughout the paleosol-loess sequence. These fossils were also found to be good indicators of monsoon variability. Rousseau and $\mathrm{Wu}$ (1999) provide evidence for drier environments based on the presence of xerophilous (dry-loving) taxa at 180 kya, 154 kya, and 138 kya. Species associated with warmer, wetter climate (hygrophilous, or water-loving taxa) were present between approximately 242 and 232 kya and at $210 \mathrm{kya}, 164 \mathrm{kya}$, and $140 \mathrm{kya}$ years ago. There is also substantial ice core evidence for rapid, abrupt climatic transitions during the last few hundred thousand years (Adams et al. 1999; Alley 2000). The time scale of these transitions is on the order of a few hundred years or even decades, suggesting that Middle Pleistocene faunal and human populations had to adapt to environmental change on a regular basis.

As relatively 'protected' environments, cave- and rockshelters are potentially important sources of paleoclimatic data. Microstratigraphic examinations of cave and rockshelter deposits have proven to be useful for identifying abrupt climatic change (cf. Courty and Vallverdu 2001). In addition, geological formations that are unique to cave environments, such as speleothems (also called 'cave calcites,' as calcite is the primary mineral component of speleothems and limestone), are important for dating cave deposits as well as providing information about paleoclimate. Speleothems are features that result from slow-moving water containing calcium carbonate, and the rate of their formation is dependent upon a dynamic system involving the carbon, water, and calcium cycles in the cave and surrounding environment (Yuan et al. 1995).

According to studies of modern cave formations, speleothem deposition is faster in warm humid, as opposed to cold dry, intervals. This occurs because in colder periods the amount of surface water is reduced and there is a lower rate of chemical deposition. During warm climates, healthy perennial vegetation provides an additional source of carbon dioxide. This greatly enhances the ability of percolating water to dissolve calcium carbonate $\left(\mathrm{CaCO}_{3}\right)$, creating favorable conditions for calcite formation inside caves (Liu and He 1990; Gascoyne 1992). The potential of speleothems for paleoclimatic reconstruction includes (1) using their growth rates to model general climate regimes; (2) using their internal stratigraphy to document sudden climate change (cf. Yuan et al. 1995: Fig. 5); (3) study of ${ }^{18} \mathrm{O}$ variations to understand changes in the ${ }^{18} \mathrm{O}$ of the water and the ambient temperature during their formation; (4) using ${ }^{13} \mathrm{C}$ variation to detect changes in ${ }^{13} \mathrm{C}$ sources and calcite precipitation; (5) analysis of ${ }^{2} \mathrm{H}$ variation in fluid inclusions to track changes in the ${ }^{2} \mathrm{H}$ of water linked to climatic variation; (6) analysis of pollen and organic inclusions to model surface vegetation; and (7) documenting trace metal content to determine changes in water composition and the ambient temperature during their formation (Gascoyne 1992: Table 1). While many of these analytical procedures are just in the developmental stages and have been tested in rather limited contexts, there is widespread interest in the analysis of 
speleothems for the reconstruction of fine-grained (in some cases at 100-year resolution) climatic changes. In the future, speleothem formations, when calibrated with radiometric dating techniques, may prove to be roughly analogous to tree rings in terms of their use in correlating regional sites and evaluating climatic fluctuations.

U-series dated speleothems in eastern China document the climatic changes of the past 350 kya (Zhang 1989). The alternating sequence of deposition and nondeposition is correlated with interglacials and glacials. Like the paleosols in loess sequences, these alternations can be compared with oxygen isotope variation and the major oxygen isotope stages. Johnson and Ingram (2001) investigated the high-resolution paleoclimate record, based on $\delta^{18} \mathrm{O}$ variation, contained in speleothems from Gansu, Central China. In one sample that began forming at $313 \pm 8.4 \mathrm{kya}$, they identified several growth hiatuses encompassing extended periods when extreme cold or dry conditions prevailed. In the past decade, several speleothems from southern China, including Guizhou, have been studied and dated (Shen 1993). A newer U-series dating technique, high-precision TIMS (Thermal Ionization Mass Spectrometry), allows researchers to accurately calibrate the growth rate of speleothems and to assess paleoclimatic signatures. For example, according to Shen et al. (1997a), there were two regional warm and humid events in Guizhou at approximately 147 kya and 138 kya.

Other paleoclimatic data, such as pollen records, are filling in this picture of climatic shifts in southern China during the Middle Pleistocene. To the southeast of Guizhou, researchers have studied an extensive lacustrine deposit $(200 \mathrm{~m})$ from the Leizhou Peninsula near the South China Sea. The sequence spans the last 400 ky and has been correlated with OIS 10 through 1. Zheng and Lei's (1999) analysis of the pollen data suggests that a marked shift in vegetation zones occurred during the cool and relatively wet conditions of OIS 8 and 6, when the montane forests lowered by at least $600 \mathrm{~m}$. An even greater shift $(800-1000 \mathrm{~m})$ in this forest zone took place between OIS 4 and 2.

Archaeologists working in Asia are now in the position where they can begin to make use of these new analytical techniques and paleoclimatic findings to relate their research to regional, continental, and global climatic data. In this paper we discuss how the geologic (including speleothem), stratigraphic, and chronologic data from the archaeological site of Panxian Dadong can be interpreted with regard to available broader-based paleoclimatic information to provide a more integrated perspective on the Middle Pleistocene paleoenvironmental of upland southern China.

\section{SITE CHARACTERISTICS}

Panxian Dadong (English translation: Panxian 'Grand Cave') is located in Panxian District, Liupanshui City, Guizhou Province. The cave location is $25^{\circ} 37^{\prime} 38^{\prime \prime} \mathrm{N}$, $104^{\circ} 44^{\prime} \mathrm{E}$ on the western part of the Guizhou Plateau (Fig. 1). The plateau has a general elevation of 1400-2000 $\mathrm{m}$ and is composed of carboniferous and permian limestones, cataclastic rocks, basalt, and coal deposits.

The Middle Pleistocene archaeological record for western South China and neighboring northern Southeast Asia is almost exclusively known from sites in 


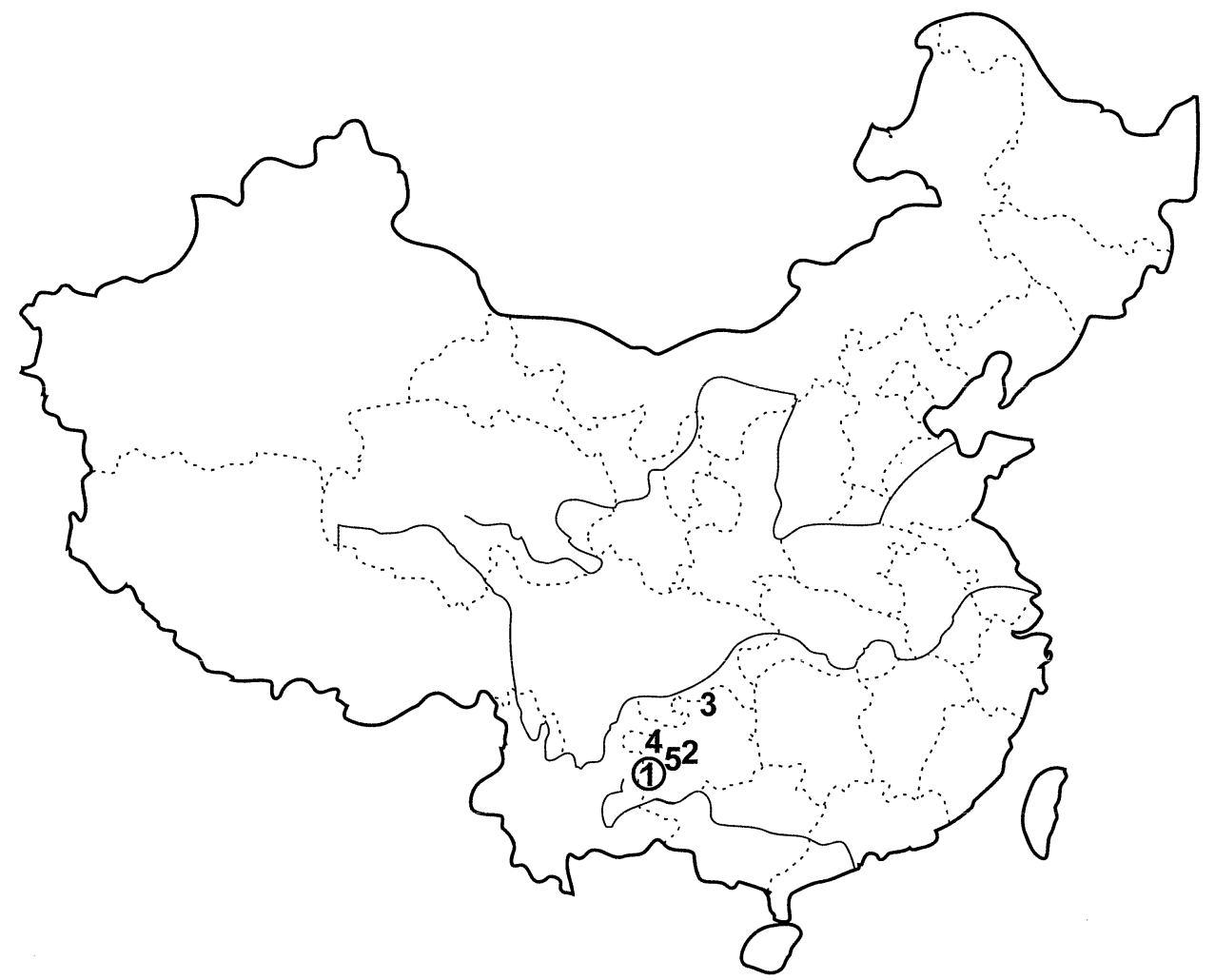

Fig. 1. Map of China with Panxian Dadong and other sites mentioned in the text. (1) Panxian Dadong; (2) Guanyindong; (3) Tongzi; (4) Bianbian; (5) Shuicheng.

upland areas similar to Dadong (Schepartz et al. 2000). Other sites in the vicinity of Dadong, such as Yanhui (Tongzi) (Shen and Jin 1991), Bianbian (Cai et al. 1991), Guanyindong (Li and Wen 1986) and Shuicheng (Fig. 1), have yielded Middle to Upper Pleistocene archaeological remains, fauna and/or hominid fossils, attesting to a widespread and sustained human occupation of the region. Dadong is the largest of these sites in terms of cave interior area and depth of deposits, and it has yielded the most extensive sample of faunal and hominid fossils.

Dadong is the middle cave in a series of three interconnecting karst caverns stacked within a $230-\mathrm{m}$-high hill. This formation of multitiered chambers is the result of tectonic uplift through the Tertiary and Quaternary eras. The Dadong hill is situated in a small valley that lies at an elevation of $1630 \mathrm{~m}$ above sea level. The eastward facing cave entrance is $55 \mathrm{~m}$ wide by $50 \mathrm{~m}$ high and is located $32.4 \mathrm{~m}$ above the valley floor. Like many of the Guizhou caves, Dadong is described as a 'tunnel cave' (Sweeting 1995:113). The main chamber narrows slightly to become an average of $35 \mathrm{~m}$ wide and $30 \mathrm{~m}$ high. It runs over $220 \mathrm{~m}$ in length, and covers an area of over $8000 \mathrm{~m}^{2}$ (Fig. 2). 


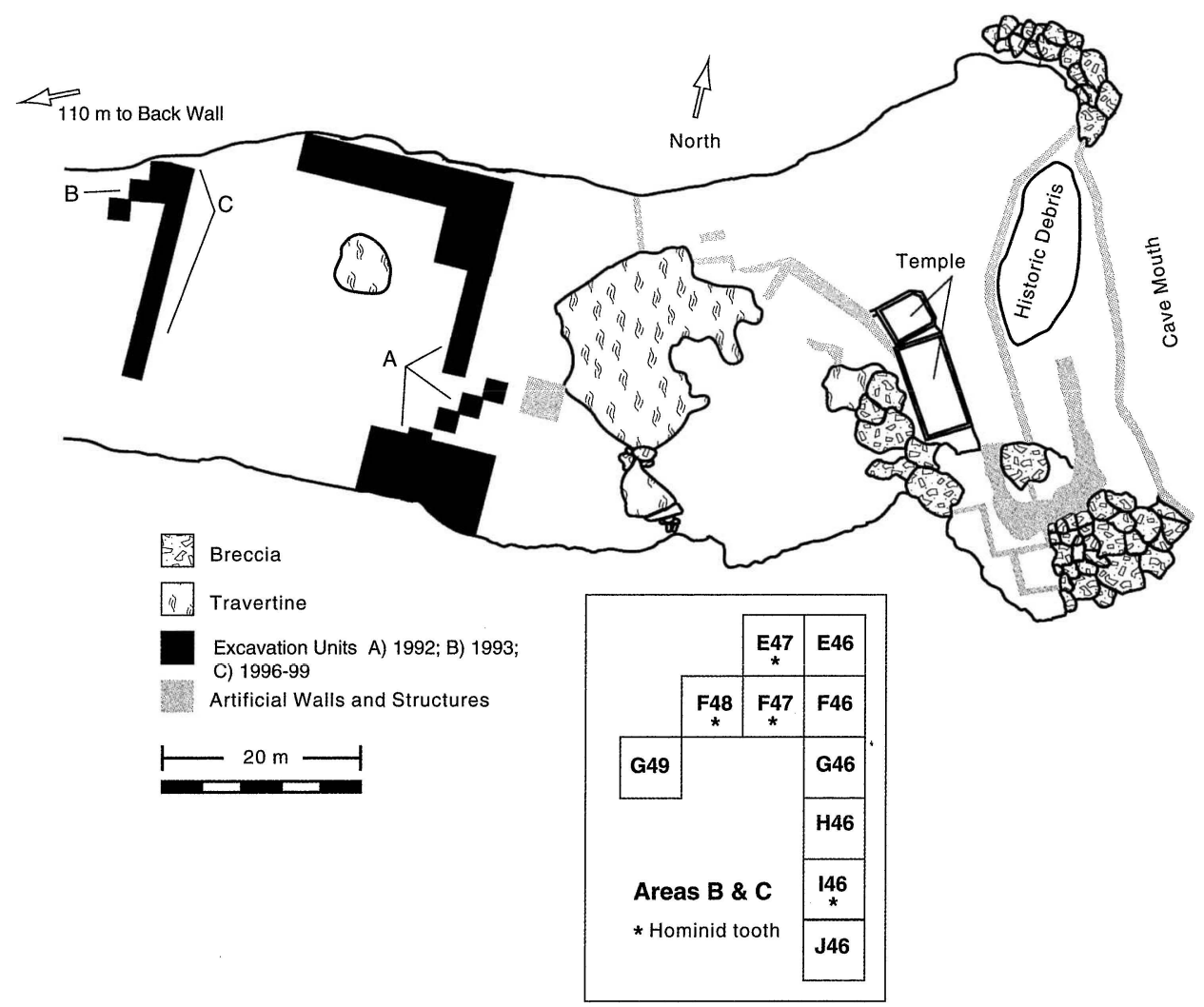

Fig. 2. Panxian Dadong main chamber excavations. The excavation area designated Area C consists of a long trench that was cleared of approximately one meter of disturbed sediments. Controlled excavations then followed in the north portion of the trench, as shown in the insert.

\section{STRATIGRAPHIC DESCRIPTION OF THE DEPOSITS}

The deposits that are the focus of paleoanthropological and geological investigation at Dadong lie beneath approximately one meter of sediments that are disturbed by recent and historical activities in the cave. Undisturbed deposits, mainly accessible in the middle of the central chamber where roof fall is less substantial (Fig. 2), were excavated in four field seasons. The surface area of Dadong is divided into two-meter-square units further subdivided into one-meter quadrants. A surface area of $36 \mathrm{~m}^{2}$ was excavated from 1996 through 2000 to a maximum depth of approximately $7.5 \mathrm{~m}$ below datum (Fig. 2 inset). Based on the profiles of squares E46 and F46 (the area where the excavation is deepest), the deposits can be divided to three major units, with the second containing two stratigraphic layers. The profile (Fig. 3), from top to bottom, is described as follows:

Unit 1 - Brown travertine $(97.55-96 \mathrm{~m})$. This unit is formed by thinly bedded travertines interspersed with loose clay fill. These impure travertines slope to the southwest at a rate of $2-3^{\circ} / 2 \mathrm{~m}$ square. The upper portion of this unit contains few piece-plotted mammalian fossils, stone artifacts, limestone, or stalactite fragments. The total thickness throughout the entire excavation area is approximately 


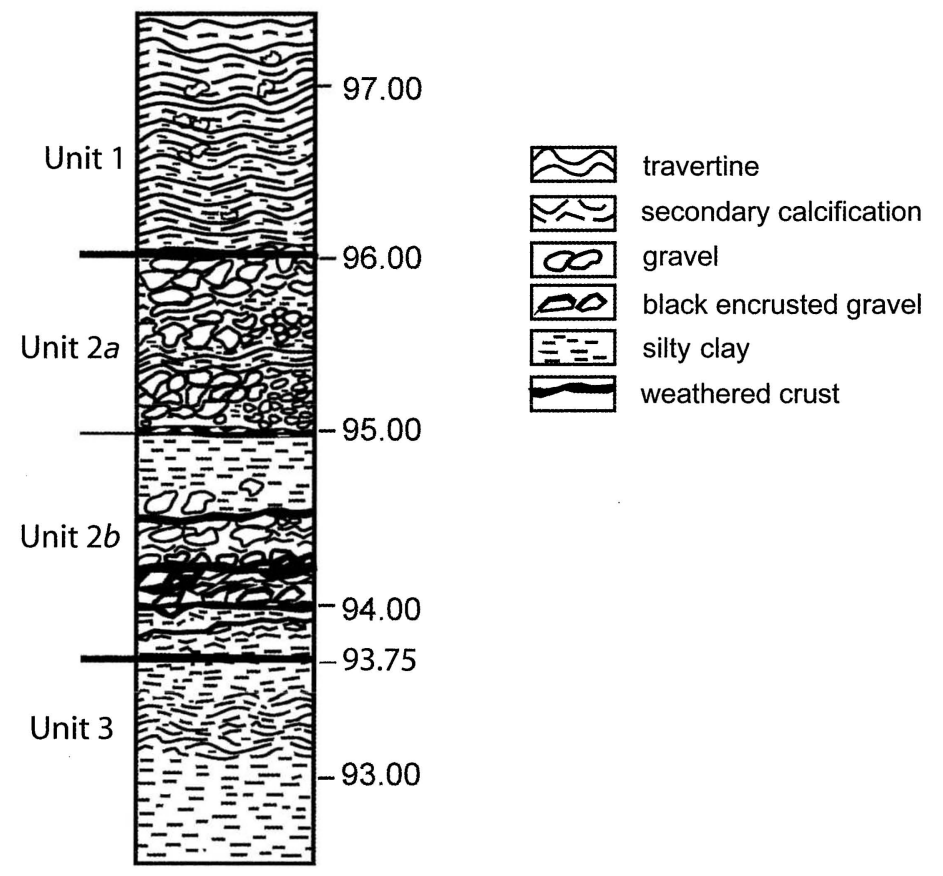

Fig. 3. Panxian Dadong stratigraphy. (Figure adapted from original drawing by P. Karkanas.)

$1.5 \mathrm{~m}$. Preliminary microstratigraphic analysis of this unit suggests that it is quite complex and that anthropogenic factors were a component in its formation ( $\mathrm{P}$. Karkanas, pers. comm.).

Unit 2 - Brown and black breccias (96-93.75 m). This unit consists of breccia, clayey sands, and travertines. The majority of the mammalian fossils, stone artifacts and three human teeth were found in this unit. It is comprised of two layers, $2 a$ and $2 b$.

(2a) Brown breccia bed (96-95 m). This brecciated deposit consists primarily of roof fall and limestone blocks along with stalactites, clayey sands, and travertines. Chert, basalt, and limestone artifacts are found in this layer. ESR date for mammal teeth in this unit yield age estimates of 137-156 kya (Rink et al. 2003).

(2b) Black breccia bed (95-93.75 m). This layer consists of breccia with gravel and clay. Large limestone boulders and stalactites within this layer are strongly weathered and covered with a thin black cement coating. A black gravel cemented sublayer clearly divides this lower layer from $2 a$ at $95 \mathrm{~m}$.

There is also a sublayer of weathered unconsolidated travertine in the middle of the layer that is observable in other profiles of the excavation. This widespread distribution suggests that the deposits throughout the main chamber can be correlated. In addition to mammalian fossils and stone artifacts, a human tooth was found in this layer during the 2000 excavation at $94.203 \mathrm{~m}$. ESR dates for this layer are based on a sample of mammal teeth from 94.9-94.0 and range from 214-262 kya (Rink et al. 2003). 


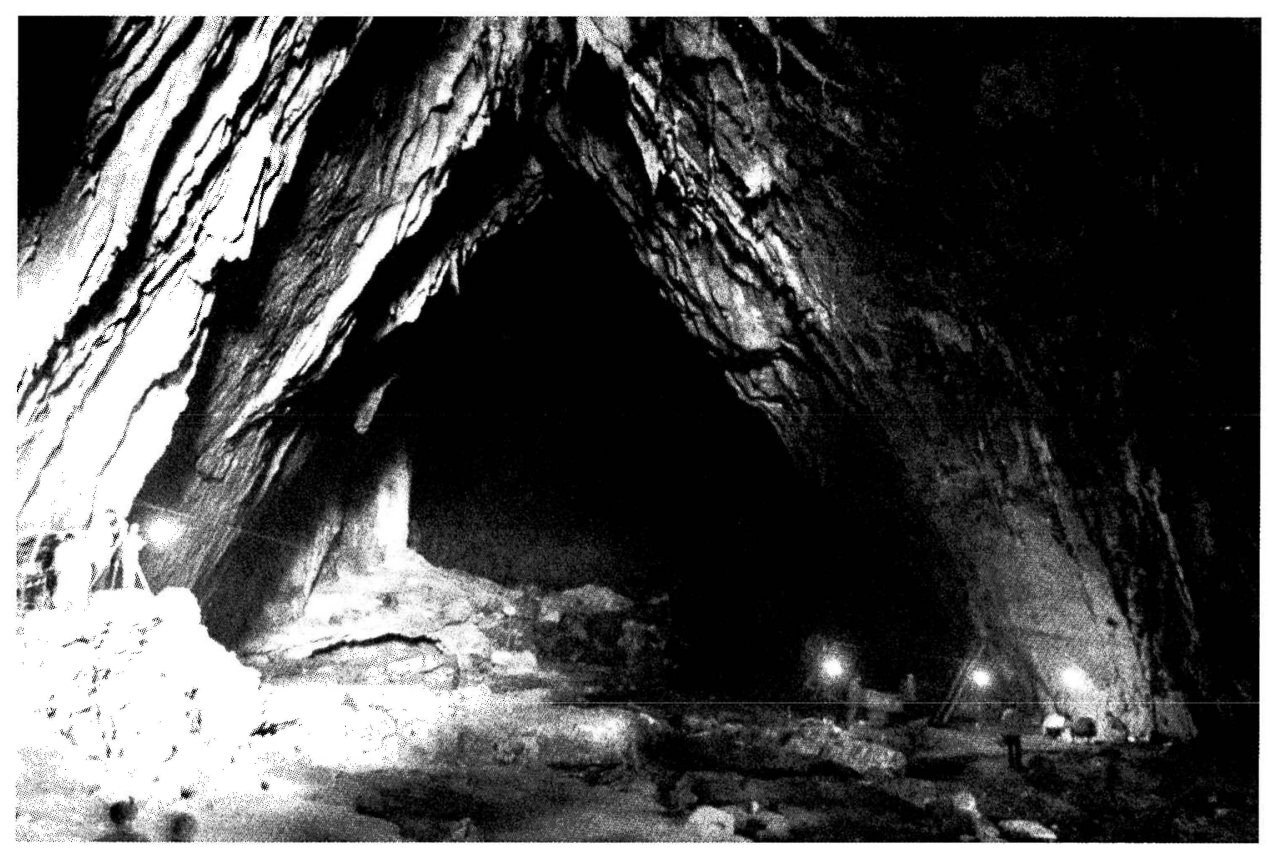

Fig. 4. Interior view of Panxian Dadong showing basic cavern structure and speleothem formations.

Unit 3 - (93.74-?). This is a clayey unit without anthropogenic remains. It begins at approximately $6.26 \mathrm{~m}$ below datum. The full thickness of this unit is unknown at present, although it has been excavated to a depth of 92.458 , or over $7.5 \mathrm{~m}$ below datum. The known thickness is therefore over $1.28 \mathrm{~m}$.

Several types of speleothems are found in Dadong's main chamber (Figs. 4 and 5). Flowstone forms most of the walls of the cave, stalagmites extend upward from the floor of the cave in many areas, and stalactites hang from the cave roof. There are also several columns in the main chamber that form from the union of stalagmites and stalactites. The most massive of these, measuring nearly $20 \mathrm{~m}$ in diameter, began forming near the entrance at approximately 169 kya (Shen et al. 1997b). Within the excavation units, the Dadong deposits contain other types of speleothems including fallen stalactites and numerous cave pearls. Pearls are concentric concretions found in shallow cave pools. They form when water dripping into the pool loses carbon dioxide and precipitates calcite. This precipitate usually forms around a nucleus of sand, bone, or other material. The typical roundness is due to the uniform growth of the pearl, rather than to any sort of rotation due to dripping (Hill and Forti 1997). The dripping causes vibrations in the pool that may prevent the pearls from cementing to the pool floor, as is the case in Dadong.

In addition to ESR dating of mammalian teeth from the excavations (Rink et al. 2003), 16 calcite samples were collected during the early stages of the investigations of Dadong (Shen et al. 1997b). These yielded a range of U-series dates for the Dadong deposits that correlate with the excavation levels (as discussed below and in Rink et al. 2003), and provide information about the major 


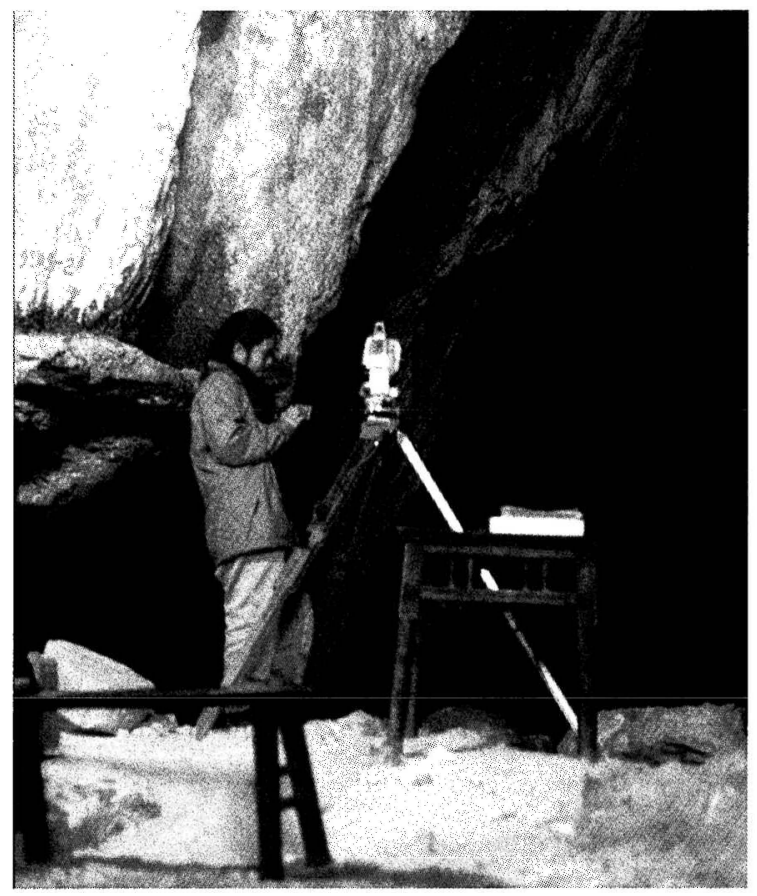

Fig. 5. Interior of Panxian Dadong illustrating flowstone formation.

speleothem formations in the cave. According to Shen et al. (1997b), the results from the calcite samples with heavy detrital contamination were discarded. For samples with a $230 \mathrm{Th} / 232 \mathrm{Th}$ ratio of less than 20 , the initial $230 \mathrm{Th}$ contribution to the age was corrected. Dates for Units $2 a$ and $2 b$ are 160 and 260 kya respectively. The date for $2 a$ comes from a relatively pure and compact flowstone layer and is considered reliable. The older date for $2 b$ is corrected because the calcite sample was less pure. These correspond to OIS 6 and then transition to OIS 7, the S2 paleosol of the Chinese Loess/Paleosol sequence and interglacials on the Qinghai-Tibet Plateau and in Europe (see Fig. 6; Shen et al. 1997b).

\section{PALEOENVIRONMENT AS RECORDED IN THE DEPOSITS}

In the Dadong deposits, the thickness of the travertine in Unit 1 (97.55-96.00 m) suggests that it was most likely formed in a warm period. U-series dates for a capping stalagmite (Shen et al. 1997b) and ESR dating on mammal tooth enamel from the layer below (Rink et al. 2003) constrain the formation of Unit 1 to between 60 and $128 \mathrm{kya}$. This corresponds partly to OIS 5 and the $\mathrm{S}_{1}$ paleosol of the Chinese Loess/Paleosol sequence. In terms of glacial chronology, Unit 1 at Dadong would correlate with the last interglacial on the Qinghai-Tibet Plateau and the European last interglacial period (Fig. 6).

Layer $2 a$ of Unit 2 has relatively less travertine (Fig. 3). U-series dates on materials corresponding to this area of the profile range from 142 to 180 kya (Shen et al. 1997b). The mammal teeth in the middle of the layer were ESR- 


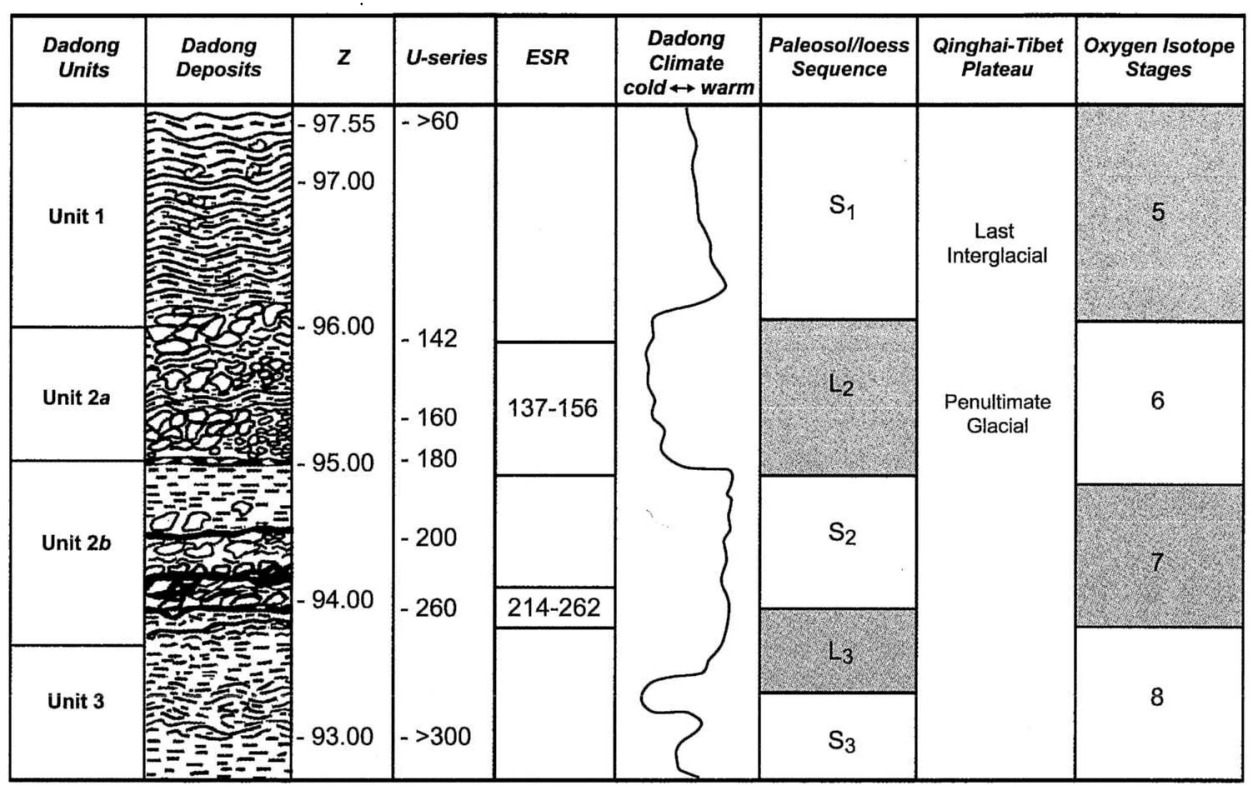

Fig. 6. Climatic and chronological correlations. $\mathrm{Z}=$ elevation in meters; U-series data from Shen et al. (1997b) are expressed in kya; ESR data from Rink et al. (2003) are expressed in kya; data other than Dadong climate are from Liu et al. (2000).

dated at 137-156 kya (Rink et al. 2003). Together, these dating results suggest that the upper layer of Unit $2(2 a)$ was deposited in a cold period including the culmination of OIS 6, the $\mathrm{L}_{2}$ loess of the Chinese Loess/Paleosol sequence and a Qinghai-Tibet Plateau glacial period (Liu et al. 2000).

Interestingly, the preliminary results of the microstratigraphic analysis suggest there was freeze-thaw activity in this unit between 95.3 to $95 \mathrm{~m}$ (P. Karkanas, pers. comm.). Further evidence for this phenomenon in other portions of the Dadong strata may be found when the detailed microstratigraphic sampling of the different profiles is completed. For freeze-thaw activity to occur, the environmental temperature must be at least $-5^{\circ} \mathrm{C}$ in north temperate latitudes (Farrand 2001). This observation of freeze-thaw activity in South China was very unexpected, but it can be interpreted as an indication of the temperature extremes that might have affected the upland regions during the late Middle Pleistocene. It is also consistent with the faunal evidence at Dadong. The more subtropical species such as pigs and primates, which are known but only in very small numbers (Bakken et al., this volume), are not present during these very cold intervals.

A weathered crust on the brecciated limestone and stalactites in Unit $2 b$ (sample from square $\mathrm{F} 46, \mathrm{z}=94.5 \mathrm{~m}$ ) may mark a transition from a colder stage to a warm/humid climate. Chemical analysis of this black encrustation (conducted by the Geological Test Center in Guangxi, China) detected a relatively rich concentration of insoluble elements from silica dioxide $\left(\mathrm{SiO}_{2}\right)$, aluminum oxide $\left(\mathrm{Al}_{2} \mathrm{O}_{3}\right)$, and iron oxide (FeO) (Wang Wei et al. 2003). This suggests that the deposits formed under warm, wet conditions. 


\section{CONCLUSIONS}

Studies of speleothem formation in the karst mountains of Guizhou suggest that warm, humid environments prevailed from 240 to 180 kya and again between 130 and 100 kya. Under those conditions, the vegetation resembled present-day subtropical rain forest. The cyclical formation of speleothems in the Guizhou caves also suggests marked climatic fluctuations in the region during the Middle Pleistocene (Shen 1993). This pattern has been detected in an array of paleoclimatic indicators, ranging from components of the paleosol/loess sequence in North China and to the pollen record of lacustrine deposits near the South China Sea (Zheng and Lei 1999). The stratigraphic sequence at Panxian Dadong reflects this same pattern of cyclical environmental change during the late Middle Pleistocene. Beginning approximately 260 kya there is depositional evidence, in the form of weathering, stalactites, and limestone blocks, for warm, wet conditions in the lower layer of Unit $2(2 b)$. This is followed by a cooler episode associated with the formation of the upper layer of Unit $2(2 a)$, which continued until approximately 140 kya. The periods of human activity recorded in the deposits at Dadong can be correlated with Oxygen Isotope Stages 5-7. The general climatic conditions during this time span included an early warmer and wetter period (OIS 7 ), followed by cooling and then temperatures low enough to leave characteristic freeze-thaw features (OIS 6). The identification of freeze-thaw activity is unexpected in South China, but Dadong's elevation on the Guizhou Plateau must have amplified the general cooling that is known for OIS 6. The later period of human activity at Dadong took place during a milder, wetter regime (OIS 5).

Correlations with the major climatic scheme indicated by OIS stages provide an overall picture of Middle Pleistocene climate change at Dadong. However, within each of the units are alternating travertines and breccias that would have formed under very different environmental conditions-suggesting that there was substantial climatic fluctuation on a finer scale throughout much of the sequence. This is supported by the preliminary microstratigraphic analyses and studies of the cave calcites, but more work is needed before the intensity and rate of climatic transitions in Dadong can be fully understood.

\section{ACKNOWLEDGMENTS}

Financial support of this work comes from the U.S. National Science Foundation, and the L.S.B. Leakey, Wenner-Gren, and Luce foundations. We also thank the Chinese National Relics Bureau for its support. Wang Wei thanks Panagiotis Karkanas (Ephorate of Paleoanthropology-Speleology, Athens, Greece), Jack Rink (McMaster University), and Heather Jones (Louisiana State University) for helpful discussions of the geology. Panagiotis Karkanas provided the schematic figure of the Dadong stratigraphy and microstratigraphic information, Kanani Paraso provided mapping assistance, and Sarah Stoutamire produced many of the figures.

\section{REFERENCES CITED}

Adams, Jonathan, Mark Maslin, and Ellen Thomas

1999 Sudden climatic transitions during the Quaternary. Progress in Physical Geography $23(1): 1-36$. 
Alley, R. B.

2000 Ice-core evidence of abrupt climatic changes. Proceedings of the National Academy of Sciences USA $97: 1331-1334$.

CaI, H., X. WANG, AND C. Xu

1991 Paleolith of Bianbian cave at Bijie County, Guizhou Province [in Chinese with English abstract]. Acta Anthropologica Sinica 10:50-7.

Chen, F. H., J. Bloemendal, Z. D. Feng, J. M. Wang, E. Parker, and Z. T. Guo

2003 East Asian monsoon variations during the last interglacial: Evidence from the northwestern margin of the Chinese Loess Plateau. http://fadr.msu.ru/inqua/nl-15/llz-abs.html

Courty, Marie-Agnes, and Josep Vallverdu

2001 The microstratigraphic record of abrupt climatic changes in cave sediments of the western Mediterranean. Geoarchaeology: An International Journal 16(5):467-500.

Ding, Z. L., J. Z. Ren, S. L. YANG, AND T. S. Liu

1999 Climatic instability during the penultimate glaciation: Evidence from two high-resolution loess records, China. Journal of Geophysical Research 104(B9) : 20123-20132.

FARRAND, WiLLIAM R.

2001 Sediments and stratigraphy in rockshelters and caves: A personal perspective on principles and pragmatics. Geoarchaeology: An International Journal 16(5):537-557.

Gascoyne, $M$.

1992 Palaeoclimate determinations from cave calcite deposits. Quaternary Science Reviews $11: 609-632$.

Hill, Carol, and Paolo Forti

1997 Cave Minerals of the World, 2nd ed. Huntsville, AL: National Speliological Society.

Ji, J. F., W. Balsam, AND C. Jun

2001 Mineralogic and climatic interpretations of the Luochuan loess section (China) based on diffuse reflectance spectrophotometry. Quaternary Research 56:23-30.

Johnson, K. R., AND B. L. Ingram

2001 High-resolution paleoclimate record based on $\mathrm{d}^{18} \mathrm{O}$ variations in speleothems from Central China. Abstract: 70-72, in 4th International Symposium on Applied Isotope Geochemistry, June 2001. Pacific Grove, CA.

Li YanXian, AND Benheng Wen

1986 Guanyindong, A Lower Paleolithic Site at Qianxi County, Guizhou Province. Beijing: Cultural Relics Publishing House.

LiU, T. S., Y. F. ShI, R. J. WANG ET AL.

2000 The comparative table of China's Quaternary stratigraphy using climate change as an indicator [in Chinese with English abstract]. Quaternary Research, Sinica 20(2):110-125.

Liu, Yuyuan, AND Jinhua He

1990 The study on the palaeoclimatic long-term variation of the speleothem (stalagmite) collected from Luozhi Cave, Guilin, China [in Chinese with English abstract]. Earth Science 15(6): 689-696.

Rink, W. J., L. Schepartz, S. Miller-Antonio, W. Huang, Y. Hou, D. Bakken, D. Richter, AND H. JONES

2003 Electron spin resonance (ESR) dating of tooth enamel at Panxian Dadong Cave, Guizhou, China, in Current Research in Chinese Pleistocene Archaeology: 111-118, ed. Shen Chen and Susan G. Keates. Oxford: BAR Monograph Series.

Rousseau, D.-D., and Naiqin Wu

1999 Mollusk record of monsoon variability during the L2-S2 cycle in the Luochuan loess sequence, China. Quaternary Research 52:286-292.

Schepartz, L. A., S. Miller-Antonio, and D. A. Bakken

2000 The paleolithic occupation of southwestern China, Vietnam, Laos and Burma. World Archaeology 32(1):1-13.

SHEN, G. J.

1993 Uranium-series ages of speleothems from Guizhou paleolithic sites and their paleoclimatic implications., in Evolving Landscapes and Evolving Biotas of East Asia Since the Mid-Tertiary: 275-282, ed. N. Jablonski. Hong Kong: University of Hong Kong Centre of Asian Studies. 
Shen, G. J., B. Gahleb, And L. H. Jin

1997a TIMS U-series dating of a stalagmite from Zhenjiadong Cave in Guizhou and its paleoclimatic implications [in Chinese with English abstract]. Carsologica Sinica 16(1):11-18.

SHEN, G. J., AND L. H. JiN

1991 U-series age of Yanhui Cave, the site of Tongzi Man [in Chinese with English abstract]. Acta Anthropologica Sinica 10(1):65-72.

SHEN, G., J. Liu, AND L. H. Jin

$1997 b$ Preliminary results on U-series dating of Panxian Dadong in Guizhou Province, S-W China. Acta Anthropologica Sinica 16(3):221-230.

SweEting, M. M.

1995 Karst in China. Its Geomorphology and Environment. Berlin: Springer-Verlag.

Wang Wei, Jun Liu, Ya-mei Hou, L. A. Schepartz, S. Miller-Antonio, W. J. Rink, Xin-qiang SI, AND WEI-WEN HUANG

2003 Stratigraphic and paleoenvironmental studies at the Dadong cave, Panxian. Acta Anthropologica Sinica 22(2): 131-138.

Yuan Daoxian, Bin Li, and Zainua Liu

1995 Karst in China. Episodes 18:62-65.

Zhang, Shouyue

1989 Palaeokarst of China., in Palaeokarst: 297-311, ed. P. Bosák, D. Ford, J. Glazek, and I. Horácek. Amsterdam: Elsevier.

ZHENG, Z., AND Z.-Q. LeI

1999 A 400,000 year record of vegetational and climatic changes from a volcanic basin, Leizhou Peninsula, southern China. Palaeogeography, Palaeoclimatology and Palaeoecology 145: 339-362.

\section{ABSTRACT}

Broad-based reconstructions of the Middle Pleistocene Asian environment are valuable sources of information that can augment our understanding of prehistoric human adaptations and expansion into East Asia. The sediments, speleothems, and geochronology of Panxian Dadong Cave serve as an example of the possible integration of this broader paleoenvironmental information with more fine-grained archaeological data. The current U-series and ESR dating results for Dadong suggest that the early human activity in the cave began at least 260 kya and continued until around 142 kya. This period correlates with Oxygen Isotope Stages 7 through 6. The lower part of the breccia (Layer 2) contains very strongly weathered dark deposits, suggesting a relatively warm climatic period from 260-180 kya that corresponds to OIS 7, followed by a cooler phase with less speleothem formation corresponding to OIS 6. The Middle Pleistocene stratigraphic sequence in the Dadong cave deposits documents fluctuating and rapid changes in temperature and humidity that are also detected in general Asian, as well as South China, paleoclimatic studies based on diverse data ranging from microstratigraphic and geochemical sediment analyses to mollusk species representation. Keywords: Middle Pleistocene, Asian paleoenvironment, stratigraphy, speleothem, Panxian Dadong, China. 